http://dx.doi.org/10.12795/PH.1990.v05.i01.01

\title{
Poesía Nacionalista en Sevilla, 1936-1939
}

\author{
José María Barrera López \\ Universidad de Sevilla
}

Un experto conocedor de la literatura de los años treinta, el profesor Gonzalo Santoja advertía sobre la generalidad de los estudios que pasan raudos por el tema de la poesía nacional-sindicalista durante la guerra, sirviéndose todos del tópico que «fija la imagen de una realidad literaria plana, machacona, monocorde y carente de interés y ventilable con una tanda de páginas plagadas de frases genéricas» ${ }^{1}$. Pero, como bien advierte el crítico «aquella realidad, como todas las realidades, no es tan llana ni simple y sí demanda mayor atención».

Si con la llegada de la democracia a nuestro país -y la consiguiente libertad de opinión- resultó lógica la dedicación y el estudio de la prohibida poesía republicana (el mismo Santoja, Caudet, Ramos Gascón, Salaün, entre otros²), es lógico pensar que ya, a cierta distancia y sin condiciones previas, se juzgue lo que fue la «poesía oficial», la poesía del bando vencedor de la contienda, la nacionalista, pero desde posturas no anacrónicas ni mixtificadoras como las observadas por la crítica en el régimen anterior, sino con mentalidad crítica-objetiva y sin el tópico al que aludiamos hace unos

${ }^{1}$ SANTOJA, Gonzalo: «Poetas fascistas», Culturas Diario 16, 1 de octubre 1988, pág, IV.

2 SANTOJA, G: «Introducción» al Romancero de la guerra civil (Ministerio de Introducción Pública, Madrid, noviembre 1936; reed. fac. Madrid, Visor, 1983); Caudet, F: «Introducción» al «Romancero de la guerra civil» (Madrid, Eds, La Torre, libro Compacto, 1978; idem: «La poesía burlesca de la guerra civil española: 1936-1939», Tiempo de historia Madrid, n, 71, octubre 1980, págs, 118-124; idem: «La poesía de la guerra civil» en AAVV, La Guerra civil. Historia 16, n, 17, 1987; RAMOS GASCÓN. A.: «Romanticismo y Romancero durante la guerra civil española» Ideologies and Literature I, 3, (1977), págs, 53-59; idem: «Introducción» al Romancero del Ejército Popular, Madrid, Nuestra Cultura, 1978; y SALAÜN, S: «Introducción» a Romancero Libertario, París, Ruedo Ibérico, 1971; idem: «Poetas profesionales y vocaciones incipientes durantes la Guerra de España», en AAVV, Creación y público en la Literatura Española, Madrid, Castalia, 1974; idem: «La expresión poética durante la guerra de España», en Harenz(ed), Los escritores y la guerra de España, Barcelona, Libros de Monte Avila, 1977; idem: La poesía de la Guerra de España, Madrid, Castalia, 1985. 
momentos. No se trata de conseguir con ello el «fenómeno que acaso pueda calificarse de "revival", con sus notas de nostalgia y seguramente de algo más» de la literatura fascista, ni tampoco de proponer un ejemplo «de compresión pluralista consensuada» ${ }^{3}$, sino simplemente de ofrecer y clarificar un período de las letras y situarlo en su justo valor, desde una perspectiva nueva. En este sentido venimos a sumarnos al estudio temprano de J. Lechner, a las aportaciones de Mainer, Mermall, Calami, Rodríguez Puertolas, Cano Ballesta, Pérez Bowie, Cortines, Cruz Giráldez y, más recientemente, de Víctor García de la Concha. Todos ellos, a lo largo de veinte años han ido componiendo el rompecabezas de este tipo de literatura ${ }^{4}$.

Por otro lado el centrarnos en Sevilla no es localismo gratuito sino evidencia de un «corpus» desarrollado a través de la prensa periódica (La Unión, ABC, FE, El Correo de Andalucía) y publicaciones de autores importantes dentro del panorama poético de la Guerra.

\section{Los «Seniors»}

El primero de ellos y más significativo es Manuel Machado, (1874-1947), considerado como «típico representante de la ideología tradicionalista ${ }^{5}$ de la poesía de guerra, «la figura más representativa, bien que no la más activa, del bando nacional» ${ }^{6}$. En el periódico $\mathrm{ABC}$ publicó, desde el 13 de octubre del 36 hasta el 12 de junio del 37, 6 poemas («Blasón de España», «Tradición», «San Ignacio de Loyola», «San Agustín»,

${ }^{3}$ RODRÍGUEZ PUERTOLAS, Julio: Literatura Fascista Española, vol, I, Historia, Madrid, Ed, Akal, col, España sin espejo, 1986, Págs, 11 y 13.

${ }^{4}$ LECHNER, Jan: El compromiso en la Poesía Española del S.XX (Parte I. De la Generación de 1898 a 1939), Leiden, Universitai Pers Leiden, 1968, págs, 208-243; MAINER, J-C: Recuerdos de una vocación generacional, I: Arte y Creación literaria en Vértice (1937-1940), Insula, 252, (1967), pág, 3, y «id, 254, pág, 9; idem: Falange y Literatura Barcelona, Ed, Labor, Textos 'Hispánicos Modernos, 1971; MERMALL, Thomas: «Aesthetics and Politics in Falangist Culture, 1935-1945», Bulletin of Hispanic Studies (1973), págs, 44-45, CALAMAI, N: El compromiso de la Poesía en la Guerra Civil Española, Barcelona, Laia, 1979; RODRÍGUEZ PUERTOLAS, J. et alii: Historia social de la Literatura Española (en lengua castella), T. III, Madrid, Castalia, 1979, págs, 47-61, idem: «Fascismo y poesía en España» Actas del VII Congreso de al Asociación Internacional de Hispanistas, Venecia, 25-30 agosto 1980, publicadas en Roma, Bulzoni ed, 1982; Rodriguez Puertolas, J.: Literatura Fascista Española, 2 tomos, Madrid, 1986-1987; CANO BALLESTA, J: «El enfrentamiento de dos retóricas: la poesía de la guerra civil», en López de Abiada 9ed,), Entre la cruz y la espada: en torno a la Poesía de Postguerra Homenaje a Eugenio de Nora, Madrid, Gredos, 1984, págs, 75-85, 'PÉREZ BOWIE, J. A.: «En tomo al lenguaje poético fascista, La metáfora de la Guardia Eterna», Letras de Deusto, Universidad de Deusto, Bilbao, n, 31, enero-abril 1985, págs. 73-96, CORTINES, J.: «La Poesía nacionalista», Ciclo Literatura y Guerra Civil, Universidad de Sevilla, septiembre 1986, CRUZ, M.: «Aspectos de la poesía Nacionalista en la guerra civil; Sobre las colaboraciones poéticas en el Romancero Histórico de la Cruzada, Conferencias en la UNED, noviembre 1986, y GARCÍA DE LA CONCHA,V.: La Poesía Española de 1935 a 1975 T.I. De la preguerra a los años oscuros, 1935-1944 Madrid, Cátedra, 1987, págs, 224-252.

${ }^{5}$ RODRÍGUEZ PUERTOLAS, J.: Historia social de la Literatura española (en lengua castellana) T. IIII, cit, pág. 50.

${ }^{6}$ GARCÍA DE LA CONCHA, V.: La Poesía Española de 1935 a 1975, cit, pág, 228. 
«España» y «Emilio Mola ¡Presente!»), que pasarían a su volumen Horas de Oro. Devocionario poético, publicado en 1938, y con dedicatoria al General Franco ( Pocos son los hombres a quienes la Providencia ha concedido el privilegio de realizar la poesía de la Historia»). El libro se abre con un Prólogo, a modo de credo del poeta, donde se unen indisolublemente Religión e Historia:

«De todo tiempo he sentido yo en mí la continuidad de la vida española. Es decir, que en mí se ha dado la Historia de España como una corriente que pasara por mi corazón... Así, ahora que vamos a nuestra España en la cumbre de un nuevo sacrificio por la Civilización Occidental, en trance de heroicidad por un ideal católico, es decir, universal, como en sus tiempos de Granada y de Lepanto...»

Concebido como una «antología» de poemas varios, éstos se agrupan en dos secciones, «Poemas españoles» y «Poemas religiosos». Ya en la primera, en sus dos apartados -«Ayer» y «Hoy»- se nos anticipa la «infraestructura ideológica del libro»? la exaltación del maridaje de las hazañas del bando nacional con las de la Edad de Oro. Si en "Ayer" se canta a «Castilla», «Alvar-Fañez», «Los conquistadores», «Carlos V» o «Felipe II», "Hoy" que se abre con un famoso soneto a Franco, se inclina a alabar la «Tradición», «España», «Blasón de España», «General Moscardó», etc....., donde el autor «sólo en alguna pieza de arte menor, la gracia del oficio salva lo convencional del contenido» ${ }^{8}$. Es significativo que el libro se cierre con una «Oración a José Antonio». Es autor no olvida a escritores como Menéndez Pelayo o Serafín Alvarez Quintero, todos ellos glorias de la Nueva España ${ }^{9}$. Este «tradicionalismo» será la base de toda la Poética nacionalista posterior: «Los poetas del fascio buscan las raíces de su obra literaria y política en el pasado, en la Tradición (....). Se hace preciso regresar a una España previa al siglo XVIII, la de Isabel, Flandes, Trento, Lepanto» ${ }^{10}$. Con estas referencias Manuel Machado pondrá en guardia contra quienes intentan abrir nuevos surcos en la historia de España ${ }^{11}$, defendiendo y exaltando el prestigio de un pueblo, de una raza que tiene por orgullo unir Patria a la Historia.

Con el libro Del Levantamiento por la Tradición de España, publicado en las Escuelas Salesianas de Artes Gráficas de Sevilla, en 1936, Felipe Cortines y Murube (1883-1961), contribuye al «conservadurismos inherente al conglomerado ideológico nacionalista» ${ }^{12}$, propio de los primeros momentos -los poemas están fechados en juliodiciembre del 36- de la cruzada. Las veinticinco composiciones presentan la forma del soneto, excepto en dos ocasiones: «Epitafio de gloria», escrita en coplas, $\mathrm{y}$ «En el puente de Bou», en cuartetas. El soneto, obras arquitectónica y artificiosa, descansa, en su estructura, sobre las columnas de dos cadenas de signos verbales: dureza, heroísmo,

\footnotetext{
${ }^{7}$ Ibidem.

${ }^{8}$ Ibidem, pág, 229.

${ }^{9}$ RODRÍGUEZ PUERTOLAS, J.: Literatura Fascista Española, cit, pág, 132.

${ }^{10}$ RODRÍGUEZ PUERTOLAS, J.: «Fascismo y Poesía en España», art, cit, pág, 885.

${ }^{11}$ Cfr, LECHNER, El Compromiso en la Poesía española, cit, pág, 210.

12 PÉREZ BOWIE, J/A.: «El enfrentamiento de dos retóricas; La Poesía...», art, cit., pág.78.
} 
aventura y blandura, verdura, molicie. Esto permite al poeta desarrollar toda una dialética entre heroísmo y molicie creando una tensión que mantiene trabados los diversos elementos a lo largo del soneto ${ }^{13}$. El utilizar los procedimientos expresivos del Siglo de Oro es característica de esta primera poesía nacionalista: suelen persistir igualmente en esta poesía algunos rasgos modernistas, si bien se trata de rasgos de carácter negativo como pueden ser «la imaginería delirante o la acumulación abrumadora de sintagmas no progresivos» ${ }^{14}$. El Generalísimo Franco, Queipo, Mola, Moscardó, Millán Astray, Cabanellas, Varela, por un lado, y espisodios en ciudades como Oviedo, Huesca son significativos de esta revitalización de los mitos de la Cruzada. Jacobo Cortines ha escrito: «Al estallar la guerra civil prestó su apoyo, a las fuerzas nacionales. Desde Sevilla siguió el desarrollo de los acontecimientos colaboraron en los periódicos locales, primicipalmente en el ABC. Para el escritor, que contaba entonces 52 años, el levantamiento contra la República significaba la salvación de los valores tradicionales de España» ${ }^{15}$.

No es de extrañar este empeño del escritor de Los Palacios, ya que, en 1908, había publicado De Andalucía Rimas, con una sección, «De mi Patria», de 18 poesías, donde se cantaba a la España Imperial, descubridora del nuevo mundo y se ofrecía semblanzas de españoles ilustres, escogidos más «por predilección del autor que a una premeditada simbología nacional» ${ }^{16}$. En otros ejemplares suyos, como Nuevas Rimas (1911) o Romances del camino (1916), también se encuentran partes con idéntica temática («De España, Amor de España»), todas ellas significativas de la defensa de los valores tradicinales y el sentimiento patriótico ${ }^{17}$, acorde con las cuatro coordenadas principales de la idología nacionalista (Imperio, Patria, Tradición, Dios) ${ }^{18}$.

José Muñoz San Román (1876-1958), autor costumbrista de innumerables obras teatrales y libros de poemas, publicó, durante la guerra, tres novelas (Las fieras rojas, 1937; Del ruedo a la trinchera, 1938 y Señorita en la retaguardia, 1938 ${ }^{19}$, pero lo más significativo de su producción civil es el poemario Ideario Patriótico (Sonetos), fechado en Sevilla, R. Flores impresor, en 1936-1937. Dedicado al «invencible Ejército español, orgullo y gloria de la Patria», consta sólo de 12 sonetos con un hilo argumental: la resurección de la Patria con su «ímpetu imperial». La identificación España=Cruz (Cristo), la redención de ambos -en sentido opuesto al poeta peruano Vallejo- («Apura el cáliz, lleno de amargura»), en sentido ascético-místico («Cuando será, Señor, que estos mis ojos,/miren llegar bajo el azul del cielo....»), como Oración a «Nuestro Padre Jesús de la Pasión» («De mi Patria, que vive desolada, /desvía la desgracia y los errores»). Las «maldades» siempre son identificadas con «la infame ralea moscovita»

${ }^{13}$ CANO BALleStA, J: «El enfrentamiento de dos retóricas; La Poesía...», art, cit, pág.78.

${ }^{14}$ PÉREZ BOWIE, J. A.: «En torno al lenguaje fascista», art, cit, pág, 77.

${ }^{15}$ CORTINES TORRES, J.: «Vida y Poesía de un Modemista andaluz». Introducción a Felipe Cortines Murube, Poemas Escogidos (1908-1961) Ateneo de Los Palacios, 1.983, pág. 63.

${ }^{16}$ Ibídem, págs, 17-18

${ }^{17}$ Ibídem, págs, 44-45

${ }^{18}$ CALAMAI, N: El compromiso de la Poesía en la Guerra Civil Española, op. cit, pág, 98.

${ }^{19}$ Cfr, RODRÍGUEZ PUERTOLAS, J, Literatura Fascista Española, cit, pág, 243. 
( ${ }_{i} \mathrm{Oh}$, furia roja en hombre disfrazada!») en este sectario nacionalismo. Frente a ella, el ímpetu guerrero, la «voluntad acrisolada» del soldado español.

\section{La «escuela» de Pemán}

El gran poema del nacionalismo, Poema de la Bestia y el Angel, publicado en Pamplona, en 1938, por José María Pemán, prototipo de composición épica entre la alegoría religiosa y la epopeya nacionalista, influyó en los poetas que, en esos momentos, publican en Sevilla. Así, el libro Poemas de la Nueva España. Moltivos líricos de la Santa Cruzada, editado por Manuel Barrios Masero (1892-1972), en noviembre de 1937, se abre con una «Carta-Prólogo» del autor de El divino impaciente, que es una Historia de la Poesía Civil desde la perspectiva conservadora:

«La guerra ha tenido para la Poesía española, eficacias de primavera (...). Yo confío que de todo este hervor,una vez que se asienten los pasos e impurezas, saldrá una definitaiva y depurada poesía civil y patriótica, género de que nuestra España andaba huérfana o poco menos.

En nuestro SIGLO DE ORO, a pesar de los grandes temas imperiales de aquella hora, apenas hay muestras del género. Acaso fue el «divino» Herrera el ingenio mejor dotado para este menester; pero la Condesa de Gelvez le sorbió el seso, le llevó por los derroteros de la metafísica amorosa y petrarquista y nos dejó sin la gran creación épica que había derecho a esperar del autor de la «Canción a D. Juan de Austria».

«Luego hay un paréntesis largo, y salvo algunas obras magníficas de Quintana, hay casi que llegar a nuestros días a algunas cosas de Marquina y otras más inmediatas de Foxá o Giménez Caballero, para encontrar una auténtica poesía civil española. De todos modos queda mucho que andar, para que España pueda, como es legítimo, hombrearse en la materia con la Italia y Carducci, la Alemania de Shiller o la Inglaerra de Rudyard Kipling».

Resulta interesante comprobar la decidida defensa del «romance» que efectúa Pemán en este Prólogo, una vez comprobada su eficacia desde el campo republicano:

«Usted ha dado a su poesía de guerra, tono y factura de romancero. Y esta del romancero es solera aromática y pura que da buen sabor a cuanto rocía. En esto sí que nuestra tradición es rica, abundante y autónoma. ¡Cómo que el romance es como el sello que da autenticidad popular a nuestras empresas bélicas! Guerra con romances -Reconquista, Indepencia, esta Cruzada Nacional- guerra auténtica, de extrañar popular. Guerra sin romance -Flandes, Italia,- guerra puramente política e imperialista (....)».

Los poemas del escritor de Sanlúcar de Barrameda recogen episodios como el 18 de julio, el Rocío de 1937 o cantos decididos al soldadito requeté o a la Bandera Española. El neopopularismo, de gran fluidez, sinceridad e intento fervor patriótico, a juicio de Pemán, no es ajeno al tono heroico de la contienda («Ay el dieciocho de Julio! / era el sol aquella tarde, / oro que se derretía/ en crisol de libertades...») el río, Triana, La Macarena, San Julián contribuyen aquí a «renacer» España, desde su Edad de Oro: «iArriba la España Lírica/de las tradiciones bellas, /de los clásicos romances/y las 
doradas leyendas/la España de Garcilaso,/de Tirso y Lope de Vega! / iLa de San Juan de la Cruz/y la de Santa Teresa!»). Quizá lo más destacable del libro sea el intento de emular al prolonguista -a quien se dedica «Confidencia de Sevilla a Toledo-, con un poema titulado «El Incendio y la Cruz» -escrito en serventesios-, cuya temática rememora otros textos del autor gaditano: «iSólo la Cruz de hierro bella y triunfante/ cual símbolo glorioso de eternidad, / se alzaba poderosa, noble y amante, / con sus brazos abiertos a la Verdad!».

Casi adelántandose a Pemán, Ramiro de Alconchel, publicó en 1937 -las palabras de presentación llevan fecha de 22 de abril-, en la Imprenta Bergalí J. D, de la calle Amor de Dios, La Novena Cruzada Poema de la guerra contra los monstruos, dedicado «a la memoria de nuestros caídos, al frente de los cuales está el nunca bastante llorado Calvo Sotelo». En el Prólogo ya advierte su autor:

«Ya muy adelantado el trabajo, me entero que el poeta Pemán, está escribiendo el Poema de la guerra. Ese será el verdadero Poema. Pero yo sigo escribiendo mi poemita, que será el producto emocional de un observador más de este cataclismo social y familiar que es la guerra española, impuesta por los monstruos marxistas».

Si el Poema de la Bestia y el Angel estaba dividido en tres capítulos o cantos (con 5,8 y 2 escenas respectivamentes) y se deslizaba desde la entrada de las fuerzas rojas del mal en la iglesia de España hasta los «Tiempos nuevos», donde se exaltaba la sanidad y firmeza de la economía de la españa Nacional, pasando por la victoria del Espítitu (el Angel) sobre la Materia (la Bestia) ${ }^{20}$, ahora, a través de 7 cantos y una Introducción, se nos conduce desde el «Surco de los Sectarios» hasta la «Expatriación de los niños en la zona roja», con los «héroes» nacionales: Franco, Queipo, Valera, Yague, Castejón, Moscardó, etc.. Significativo es el «mea culpa» de Alconchel inserto en el Canto I: «Yo también me arrepiento de haber sido, / como Espronceda, un hombre liberal, / una de esas personas que han creído / que en los reyes estaba todo el mal; / un joven que pecó y ha discutido / a la Iglesia, maestra moral, / por los años aquellos que sufrían / España las colonias que perdía».

Otro autor escasamente citado es Vicente Sánchez Arjona (Del Período Marxista, Poesías, Sevilla, Imprenta de la Divina Pastora, 1938).

\section{Los Poetas de «Mediodía». El caso Guillén}

La revista «Mediodía» se interrumpió en el número 16 -año 1933-, y no volvió a aparecer hasta 1939 como «Cuadernos de Poesía Española», con dos números $(17,18)$, dedicados a Jorge Guillén y Adriano del Valle, respectivamente ${ }^{21}$. El poeta del Cántico reproduce, en página sin numerar, la poesía de Paul Caludel «A 1 "Espagne"», a modo de prefacio del libro La persecution religieuse en Espagne (1937), que el mismo Guillén

${ }^{20}$ Cfr, LECHNER, J: Op, cit, págs, 218-225 y idem: «Pemán: Entre el Angel y la Bestia», Quimera, Barcelona, n, 12, octubre 1981, págs, 8-12.

21 VALENCIA JAÉN, J: Indice Bibliográfico de la revista Mediodía", Archivo Hispalense, Sevilla, t, XXXIV, núm, 105, 1961, págs, 177-184. 
traduciría al español, publicándose en la Secretaría de Ediciones de Falange de Sevilla el 29 de octubre de 1937. En ese mismo número de la revista sevillana, en su suplemento, Arenal de Sevillla (n.1, 1939), se incluye un pequeño artículo de Manuel Díez Crespo, «España y Claudel» (págs. 43-44), donde se aclara la composición del poesta católico respeto a nuestra guerra civil, y otro del también escritor ecijano, sobre «Plenitud de ser: cifra de Guillén en la poesía española» (págs, 12-19), donde se resalta la «seguridad» de la poesía de Guillén, frente al mundo caótico en que se encuentra la poesía de la inmediata posguerra ${ }^{22}$. La publicación de «A los Mártires Españoles» ${ }^{23}$ así como otros hechos, como el encargo del Rector D.Mariano Mota de pronunciar la lección inaugural del curso 1936-37 de la Universidad de Sevilla o la conferencia sobre Santa Teresa en la Sección Femenina, en 1.938, desvelados por Miguel Cruz, en $1985^{24}$, son acontecimientos de triste recuerdo en la biografía de Guillén, «actos de pluma sometida» como dirá después en Carta al Profesor Lechner ${ }^{25}$. Las Tertulias y amistades del entonces Catedrático de Literatura con los escritores del grupo «Mediodía», muchos de ellos vinculados a Falange Española, a través de F. E. (José María del Caballero, Manuel Halcón, Manuel Díez Crespo, Joaquín Romero Murube, Eduardo Llosent y Marañón...), hicieron posible esas conexiones ${ }^{26}$.

Los «nuevos escritores» sevillanos, en consonancia con su propia evolución idológica, se vuelcan desde los inicios de la guerra en un tradicionalismo religioso, una recreación «artística» de la ciudad y en un conservadurismo político, todo ello en el «resurgir» de un nuevo idealismo. Así lo ve Joaquín Romero, ya desde el principio de la contienda, desde el diario F. E. en su artículo «Mientras dura la guardia»:

«A media noche, vigilante bajo las estrellas de Agosto, en este puesto de guardia entre la ciudad y el campo, hay momentos de tal serenidad, de un silencio tan alto y tan puro que a no ser por el uniforme y por el cañón del fusil que, ocioso, se recuesta sobre nuestro pecho, nos creeríamos libres de nuestras obligaciones de patria, y que todo lo acontecido en estos días no ha sido más que una pesadilla de crímenes y monstruosidades. Pero estamos en pie de guerra, y de la guerra más dura, porque el enemigo está entodos los terrenos, hasta en los del corazón. Sabemos bien que todas estas reflexiones pueden quedar cortadas en un momento o por una descarga contra el enemigo.

«Lo más admirable es el espítu de estos grupos. Conozco bien a mis compañeros de guardia. Tenemos todos casi la misma edad; de treinta a treinta y cinco años. Es decir, somos en España la generación de la postguerra europea, la generación más triste, más escéptica, más pobre entre las últimas generaciones. Hasta ayer éramos todos antimilitaristas: no por nada, sino porque así lo determinó el hecho ocasional de nuestro

22 Ibídem, págs, 179-180.

${ }^{23}$ En Sevilla, Secretaría de ediciones de Falange, 29 de octubre 1937.

${ }^{24}$ CRUZ GIRÁLDEZ, M: «Jorge Guillén y Sevilla (Nuevas notas)», Archivo Hispalense, Sevilla, n, 209, septiembre-diciembre 1985, págs, 100-103.

${ }^{25}$ LECHNER, J: Op. cit, 212 y 236.

${ }^{26}$ cfr, DIEZ CRESPO, M: «El compás de Santa Clara», «Ese árbol de piedra y sueño», ABC, 19 noviembre 1984, resp, cit, por M. CRUZ, «Jorge Guillén y Sevilla», art, cit, pág, 93. 
nacimiento, de nuestra edad. Los cuentos de nuestra infancia fueron los partes del frente de combate y las reseñas terroríficas de la guerra europea.

«Luego viene la paz, llena de banderas y campanas, cuando todos los campos de la civilización son mares inmóviles de cruces. Wilson, la S. D. N. «La Modelo». En las cancillerías, Briand y Stresemann. En la literatura, Remarque, Glaesser, Barbusse... Nuestra primer amante, la mujer de una víctima de la guerra. En esta Europa deshecha, horrorizada de su obra, sin sangre ni músculos jóvenes, cumplimos nosotros 20 años y nos instalamos como hombres en el mundo.

«Sigueron las parcas su devanar de días. Nuevas generaciones han florecido. Ya menos escépticas, menos irónicas, más románticas. Estos jóvenes de hoy nos abren panoramas que no conocieron nuestros 20 años perdidos en la literatura y en la decadencia de Europa. Nos hablan de trágicas realidades y se nos imponen decididamente, barrenándonos con sus palabras en la entraña de una zona sentimental, virgen o intacta, perdida en la indisciplina caótica de nuestra formación ante la vida. Tenemos voluntad de Imperio...nos dicen. Creemos en la suprema realidad de España. España volverá a buscar su gloria... Al conjuro de estas palabras nos sentimos otra vez jóvenes, fuertes e invencibles. Tersos los nervios, duros los músculos, apretado el fusil entre nuestros brazos. Estamos de guardia desgarrón vital de unos gritos de hombres: ¡¡Arriba España!!

«Nos llega el relevo. Fusil al hombro, vamos tristes de gloria y deseo. ¿Qué es nuestra vida por España?» ${ }^{27}$.

El mismo Romero Murube (1904-1969), que colaboran en la Antología poética del Alzamiento (Cádiz, 1939) -al igual que E. Llosent-, y en Isla (n.11 «Bécquer y Sevilla», «Canciones», 15,1939; «Tarde de Sevilla» 16,1.939 y Vértice («Castilleja de Guzmán», n, 10, mayo 1938) así como en el suplemento Arenal de Sevilla («Francis Jammes, poesta de lo cotidiano y de lo mínimo», n, 2, suplemento de Mediodía, n, 18, 1939, págs, 28-31), publica en Sevilla, en edición de 37 ejemplares, Siete Romances (1937) reseñado por Juan Sierra en F. E., el 15 de febrero de1938, dedicado significativamente a Lorca: « $\mathrm{A} A$ tí, en Vizna, (sic) cerca de la/ fuente grande, hecho ya tierra/ y rumor de agua eterna y/oculta!.» El último de esos poemas, «Romance del crimen», parece referirse al poesta granadino ( Y en todo el mundo la prensa/ llevará con gran detalle/ a los hogares honrados/ cinco columnas de sangre»), pero en realidad, el autor de Sombra apasionada estaba reproduciendo sin variantes su poema «Aleluya del crimen», publicado con anterioridad en el número 14, de Mediodía («Los asesinos», n, 14, febrero de 1929, págs, 3-4), donde, a juicio de Daniele Musacchio, combina «varios de los mitos de las vanguardias, del Simultaneísmo al Surrealismo, de Blaise Cendrars a Salvador Dalí» ${ }^{28}$. Más interesante parece el «Romance del Gobernador de Sevilla», dedicado a José Cruz Conde, en la línea del anterior: «-Yo soy el Gobernador/ de Sevilla...¿Quién se atreve?/ Los generales me huyen./El dictador me obedece./ Yo mendo lo que me cuadre/ y en cordobés, aunque pese».

Por otra parte, la muerte de Lorca conmovió también a otros poetas nacionalistas. Juan Sierra, en su libro último de poemas, Alamo y Cedro (Sevilla, 1982), le dedica

${ }^{27}$ ROMERO MURUBE, J: «Mientras dura la Guardia», F. E., Sevilla, 3 septiembre 1.936, pág, 10.

${ }^{28}$ MUSACCHIO, D: La revista Mediodía de Sevilla, Sevilla PUS, 1980, pág,132. 
«Mejor si no fuistes nunca» -en advertencia a Rafael Alberti-, en el tono de «Romance del crimen», verdadera protesta y denuncia del asesinato cometido: «Aquel amor fue arrastrado/ por la traición llena de baba./ Aquel vuelco de tu cabeza/ fue peor que el de las balas./ Aquel color de tu corazón/ fue raído por la alborada». Otro texto de Alamo y cedro, «Cogida y muerte de Federico García Lorca» recuperada la Voz de Federico, desde la Voz del Espíritu. Juan Sierra (1901-1989) había publicado en la Corona de Sonetos en honor a José Antonio Primo de Rivera (Pamplona, 1939), en Vértice ( $\mathrm{El}$ hundimiento de Baleares» $\mathrm{n}, 18$, enero 1939) e Isla («A un amigo en su casamiento» $\mathrm{n}$, 12, 1938; A la Memoria del capitán Haya, n, 15, 1939; En la marcha de un amigo, n, 17, 1939). Muchos de estos textos pasarán más tarde a Claridad sin fecha (Sevilla, 1947). El Capitán Carlos de $\mathrm{Haya}^{29}$, el crucero de la flota nacinalista Baleares, el comandante Ricardo Arjona o el Bombardeo de Sevilla-Cruz Roja-, son motivos de su poesía comprometida.

Rafael Laffón (1900-1978), en su volumen, A dos aguas (Madrid, 1962), publica «Muerte y Pasión de Federico García Lorca», en dos momentos, donde, según M. Cruz, «desarrolla el símbolo de la muerte del autor del Romancero Gitano en un lugar indeterminado, dentro de la corriente elegíaca que la trágica muerte de Lorca inspiró en la poesía contemporánea» ${ }^{30}$. El autor de Vigilia del Jazmín editó en Vértice, «Salinas» (n, 12, julio 1938), «unos discretos dodecasílabos modernistas, profundamente influidos por el sector andaluz de esta escuela» ${ }^{31}$, y «Coplas a la pura y limpia Concepción de María» (n, 17, diciembre 1938), «quintillas bien construidas que recuerdan la espiritualidad clásica de nuestro Siglo de Oro («Soy barro... Más si a esa esfera/ llegan, Señoras, mis loores,/ liberal tu mano quisiera/hacer de mi barro flores, / en la eterna primavera ${ }^{32}$. Laffón también daría a la luz sus versos y su prosa en Isla («A cuerpo limpio (Sacramento) n, 10, 1937, Trémulo y vago», n, 11, 1938; «Los maestros imagineros (Doctrina y leyenda», $n, 14,1938$; «Ser y estar», n, 16, 1939; «A un amigo feliz en su partida», n, 20,1940) y continuará el tema «épico y heroico» de la contienda en algunas composiciones posteriores, como la serie «Los sonetos de España», incluida en la sección I, «Varia Silva» de Poesía (Sevilla, Aljarafe, 1945), «un trípico de poemas épico-líricos de indudable tono herreriano ${ }^{33}$ : «Para morir al militar alarde/ proclamas fiel, con voluntad serena,/ que nunca es tarde si la dicha es buena,/ aunque por Dios y Patria siempre es tarde» (Un soldado, ibídem, pág, 35). En F. E., diario de la Falange sevillana, Laffón publica unas reflexiones filosóficas sobre aspectos del carácter y el ser de la cultura, en consonancia con el momento político:

${ }^{29}$ El capitán Carlos de Haya, de estatura gigantesca, pilotó aviones Junkers durante la mayor parte de 1937 y fue abatido por un «Chato» a principios de 1938, después de efectuar 300 vuelos.

30 CRUZ GIRÁLDEZ, M: Vida y Poesía de Rafael Laffón, Sevilla, Publicaciones de la Excma. Diputación de Sevilla, 1984, pág, 325.

${ }^{31}$ MAINER, J-C. : «Creación Literaria en el libro Vértice (1937-1.940)», Insula, 254, pág, 9.

32 Incluidas después en el libro Poesías (Ed, Aljarafe, 1945).

${ }^{33}$ CRUZ GIRÁlLEZ, M: Op, cit, págs. 212. 
«(....) Y el júbilo de esta solidaridad universal de lo orgánico que el orden externo nos hace sentir difusamente, se eleva al tono de una voz autoritaria -alegría de la fe y del dominio del propio destino-, al contacto vertical de la disciplina» ${ }^{34}$.

El director de F. E., Manuel Díez Crespo (1911) -desde 1932 vinculado a Mediodía-, publicará en Jerarquía «Dolor de Primavera», en tres partes, «Muerte, Paz y Triunfo», ( $n, 4$, otoño 1938), unos endecasílabos estructurados como Cuartetos sin rima, con un surrealismo «vivencial» que trasciende el momento histórico, «el poema está matemáticamente pensado y bellamente escrito. El metro usado es el endecasílabo blanco, de amplio ritmo musical y ondulación polícroma», según escribió Juan Ruiz Peña, en Isla ${ }^{35}$, revista donde también colaborara el autor ecijano de Memorias y deseos («Elegía», n, 12, 1938; «Adriano Azul», n, 14, 1938).

Adriano del Valle, aunque no directamente vinculado a Mediodía-antes lo había estado en Papel de aleluyas- fue uno de los homenajeados en 1939 por el grupo y editó en Sevilla, en ese año, Lyra Sacra «Romances en honor de la Inmaculada Virgen María» (1933-1937), Premio Sánchez Bedoya de la Real Academia Sevillana de Buenas letras $^{36}$, que más tarde incluiría en Arpa Fiel (1930-1939) (Madrid, Col. Santo y Seña, 1941). Sus entregas serían numerosas en Vértice ( «Romance a la muerte de Fernando Villalón», n. 16, noviembre 1938; «Héroe. En memoria de Pedro de León, muerto en combate», n. 17, diciembre 1938), Jerarquía («Soneto a Garcilaso, Soneto al Río Tajo, Soneto a Bécquer», n, III, marzo 1.938) e Isla («Tres sonetos a Bécquer», n. II, 1938; «Soneto a la muerte de un amigo», n, 14, 1938; «Viaje a Tarfía con adioses para F. Villalón», n, 16, 1939; «Cuatro sonetos a Italia», n, 17, 1939) así, como F. E., con glosas sobre Octavio de Romeu (Eugenio D’ors) y Fernando Villalón («Conversaciones con Octavio de Romeu, Glosa llamada de la ciudad de Venecia y de la historia de un calamar del Adriático», 5 marzo 1937; «Postrimerías de Fernando Villalón, héroe de arpa y garrocha. I. La garrocha; II. El Arpa; III. El paisaje; IV. El carácter» 17 abril, 23 abril, 5 mayo y 8 de mayo de 1937). Su compromiso político más claro es su aportación a la Corona de Sonetos en honor a José Antonio Primo de Rivera (1939) y esa «Fidelidad a España» de Arpa Fiel: «Vivió, clamó y murió verticalmente,/ cambiando con el plomo la sonrisa. Epitafio a José Antonio».

Como resumen de las posturas de los poetas sevillanos ante la Guerra, Joaquín Romero Murube escribe en $F$. E., sobre «La guerra y los Escritores» (5 enero 1937):

«¿Cuál ha de ser la manifestación literaria de la actual guerra española? A la larga, es casi imposible precdecirlo. Ya sabemos cómo nuestra lucha no es comparable con ninguna otra. Es absoluta en todas sus medidas, y al carecer de matices, deja escasísimo margen para el relieve intelectual: aquí no hay más que dos colores y que dos palabras: Sí o no, Rojo o azul.

«Al tratar de la guerra y de la poesía conviene plantear la cuestión con claridad. No confundamos, como se ha hecho, el acto de la guerra con la poesía de la guerra.

\footnotetext{
${ }^{34}$ LAFFON, Rafael: «La huella de las horas. Desfiles», F.E., 8 marzo 1937, pág. 3.

${ }^{35}$ RUIZ PEÑA J.: «Dolor de Primavera», Isla, n, 18-19, 1939.

${ }^{36}$ En edición de bibliófilos, 40 ejems. numerados.
} 
Poesía es, estimológicamente, creación. No olvidemos que la épica es siempre anterior a la lírica. Primero fue la conquista de Troya; luego la Iliada, José María Pemán, trata de revalidar las razones de una poesía épica y narrativa en nuestro tiempos. Y lo hace con mayor honradez: sometiéndose a la prueba y forjando su poema de magníficas estrofas....

«¿Conseguirá que perdure como expone lírico de nuestro trágico hito vital?.No, lo sabemos: se ha afirmado últimamente que lo épico en nuestra época no cabía más que en el modo novelístico disforme y polifaciales de un John dos Passos o de un Aldous Huxley. Hay algo difuso y hondo, muy difícil de concretar en palabras, que nos ha hecho entrever en estos últimos años cómo el concepto de la poesía se ha unificado por las clasicas distribuciones académicas. Tal vez en el fondo no haya más que un modo de situarse frente a la producción del fenómeno poéstico. Por lo que respecta a nosotros, con toda sinceridad y sin el menor atisbo de «literaturizar» lo más mínimo, no sabemos hasta qué punto Ercilla hubiera escrito alguno de los cantos de la Araucana si hubiera dispuesto a tiempo de un buen teléfono o de una emisora en condiciones....

«¿Cuál será la literatura de nuestra guerra? Desgraciadamente algo más que el hermoso poema del poeta gaditano. La poesía de la guerra es algo más, mucho más, que el acto -épica- de la guerra. No todos, querido José María I Pemán I, hemos ido al frente como voluntarios, los días que hemos querido y en coches más o menos confortables.... Yo he visto algunos poestas de esos que llaman «de vanguardia» los que no saben una palabra de estas cuestiones, arrastrándose por los barrizales del campo y alguno -veinte años apenas- sitiéndose taladrar las entrañas por el plomo derretido de las balas explosivas.... He visto también algunos hospitales.... No creo que esta generación haga octavas reales. Tampoco espero un grito final -ya está hecho- a lo Barbusse o a lo Glaeser-.

«Pero por mi imaginación aparecen algunos personajes enigmáticos e inolvidables. Me acuerdo, p. ej. en este instante del marido -no del amante- de Lady Chatterley, en la terrible obra de Lawrence...

«iiAy la guerra!!»

Épica -Pemán- y Lírica -Mediodía- de una poesía de guerra «imperial»:

«De la poesía hay que hacer un culto en España, porque de la poesía nace la posibilidad del Imperio» ${ }^{37}$. 
